\title{
Extracellular vesicles carrying miRNA-181b-5p affects the malignant progression of acute lymphoblastic leukemia
}

\author{
Wei Yan' ${ }^{1}$ Li Song ${ }^{2}$, Huihan Wang ${ }^{1}$, Wei Yang ${ }^{1}$, Liang Hu${ }^{3}$ and Ying Yang ${ }^{1 *}$
}

\begin{abstract}
Objective: To investigate how serum extracellular vesicles (EVs)-carried miRNA-181b-5p affected the proliferation, cell cycle and apoptosis of acute lymphoblastic leukemia (ALL) cells.

Methods: Differentially expressed miRNAs related to ALL were screened by bioinformatics analysis, and the localization of target miRNA was searched by its expression. qRT-PCR was adopted to confirm the expression of miRNA$181 \mathrm{~b}-5 \mathrm{p}$. Flow cytometry and fluorescence microscopy were applied to evaluate EVs internalization. MTT assay was employed to verify the proliferation of ALL cells. Cell cycle and apoptosis were analyzed by flow cytometry. Transwell assay was applied to evaluate migration and invasion abilities.

Results: High expression of miRNA-181b-5p was proved in ALL cell lines, and miRNA-181b-5p enriched in the exosomes and vesicles of blood cells. In the meantime, it was found that EVs carrying miRNA-181 b-5p could be internalized by ALL cells and thus the expression of miRNA-181b-5p was up-regulated. Cell function assays showed that the proliferation, migration, invasion abilities of ALL cell lines were promoted in miRNA-181b-5p mimic group or the group co-culturing ALL-derived EVs and BALL-1 cell lines. The percentage of cells in G0/G1 phase was reduced and cell apoptosis was also inhibited.
\end{abstract}

Conclusion: miRNA-181b-5p carried by EVs in peripheral blood of ALL patients can enter ALL cells and thus promote the malignancy of ALL cells.

Keywords: miRNA-181b-5p, ALL, Extracellular vesicles, Proliferation, Cell cycle

\section{Introduction}

Acute lymphoblastic leukemia (ALL) is a kind of tumor derived from the abnormal proliferation of B-lymphoblasts or T-lymphoblasts in the bone marrow. Due to the fast onset, patients with ALL, if not treated in time, can only survive for from a few weeks to several months. However, the overall survival (OS) rate of adult patients who underwent allogeneic hematopoietic stem cell transplantation could be increased from $15-45 \%$ to $27-65 \%$

\footnotetext{
${ }^{*}$ Correspondence: sj_yangy@163.com

1 Department of Hematology, Shengjing Hospital of China Medical University, Shenyang 110000, People's Republic of China

Full list of author information is available at the end of the article
}

[1, 2]. ALL accounts for about $20 \%$ of adult leukemia cases while the disease is more prevalent in childhood (0-9 years old), accounting for more than $70 \%$ of childhood leukemia [3]. From the current treatment of ALL, the cure rate of child patients with ALL is close to $90 \%$ [4], but the treatment for adult patients with ALL is still facing great challenges $[5,6]$.

Recently, extracellular vesicles (EVs) have attracted much attention in cancers because of the potential of EVs as unique biomarkers or intercellular mediators, and functions against metastasis and recurrence $[7,8]$. Exosomes and micro-vesicles (MVs) are two major subtypes of EVs $[9,10]$ that are produced by healthy cells or cancer cells and can be detected in multiple body fluids, original author(s) and the source, provide a link to the Creative Commons licence, and indicate if changes were made. The images or other third party material in this article are included in the article's Creative Commons licence, unless indicated otherwise in a credit line to the material. If material is not included in the article's Creative Commons licence and your intended use is not permitted by statutory regulation or exceeds the permitted use, you will need to obtain permission directly from the copyright holder. To view a copy of this licence, visit http://creativecommons.org/licenses/by/4.0/. The Creative Commons Public Domain Dedication waiver (http://creativeco mmons.org/publicdomain/zero/1.0/) applies to the data made available in this article, unless otherwise stated in a credit line to the data. 
such as blood, urine or saliva [8]. EVs can deliver bioactive molecules from one cell to another, like functional RNA and proteins $[11,12]$, and membrane EVs are carriers delivering information to receptor cells [13]. Several studies reported that EVs derived from cancer cells relate to microRNA (miRNA) enrichment in biological fluids of patients with cancers, suggesting that miRNA may be a marker to predict the prognosis of cancer $[14,15]$. Li et al. found that 182 miRNAs and 166 miRNAs were differentially expressed in Nalm-6-MVs and Jurkat-MVs respectively, and these abnormally expressed miRNAs target a variety of oncogenes, tumor suppressor genes and signaling pathway genes, which may be involved in the progression of B-ALL or T-ALL [16]. Nevertheless, works are still less focused on the delivery of miRNAs from EVs into ALL cells and on their effects in the procession of ALL.

Herein, the expression level of miRNA-181b-5p in serum EVs from patients with ALL or healthy people was evaluated. miRNA-181b-5p was proved remarkably upregulated in EVs derived from ALL patients, and it might be a regulator in ALL cells.

\section{Materials and methods Bioinformatics analysis}

Expression microarray GSE56489 of ALL related miRNA was obtained from GEO database (https://www.ncbi.nlm. nih.gov/geo/). R "limma" package was used to perform differential analysis, with the control of normal samples, and $|\log F C|>1.5$ along with adj.pvalue $<0.05$ was used as the screening standard of differentially expressed miRNAs (DEmiRNAs). On the EVmiRNA database (http:// bioinfo.life.hust.edu.cn/EVmiRNA\#!/), the expression of the target miRNA was localized.

\section{Peripheral blood collection and serum separation}

Peripheral blood samples were obtained from 14 ALL patients and 14 healthy individuals with vacuum SST II tubes (Becton Dickinson, BD, Franklin, NJ, USA), and the serum was collected after the centrifugation of samples at $1100 \times g$ for $20 \mathrm{~min}$. All serum samples were stored at $-80{ }^{\circ} \mathrm{C}$ for use.

\section{Cell line and culture}

ALL cell line BALL-1 (BNCC102176) was procured from BeNa Culture Collection. The cell line was cultivated in a moist incubator containing $5 \% \mathrm{CO}_{2}$ at controlled temperature of $37{ }^{\circ} \mathrm{C}$. The culture medium was RPMI-1640 (HyClone, Logan, UT, USA) with 10\% fetal bovine serum (FBS) supplement (Gibco, Grand Island, NY, USA).

\section{Cell transfection}

miRNA-181b-5p mimic, mimic NC, miRNA-181b-5p inhibitor, inhibitor NC were acquired from GenePharma (Shanghai, China). BALL-1 cells were seeded in a 6-well plate and transfected with mimics adopting the Lipofectamine 2000 reagent (Invitrogen, Carlsbad, CA, USA). After $48 \mathrm{~h}$, the cells were gathered for subsequent assays.

\section{RNA extraction and qRT-PCR assay}

TRIzol reagent (Invitrogen, Carlsbad, CA, USA) was employed to extract total RNA from human peripheral blood samples and cancer cells. As for quantifying the expression of miRNA-181b-5p, complementary DNA (cDNA) was synthesized by the miScript reverse transcription kit (Qiagen), and qRT-PCR assay was conducted with the SYBR Premix Ex Taq (TaKaRa, Otsu, Shiga, Japan). U6 was the internal reference of miRNA181b-5p. $2^{-\Delta \Delta \mathrm{Ct}}$ value was used for data quantification and normalization. The qRT-PCR was performed by the Applied Biosystems 7500 system (Applied Biosystems, Warrington, UK). Primers adopted were: miRNA181b-5p: forward primer $5^{\prime}$-CCAGCTGGGCTCACT GAACAATGA-3' and reverse primer $5^{\prime}$-CAACTGGTG TCGTGGAGTCGGC-3'; U6: forward primer 5'-GCT TCGGCAGCACATATACTAAAAT- $3^{\prime}$ and reverse primer 5'-CGCTTCAGAATTTGCGTGTCAT-3'

\section{Western blot}

After the transfection, the cells in each group were washed with cold phosphate-buffered saline (PBS) 3 times, and then cell lysis was conducted on ice for $10 \mathrm{~min}$ after cell lysis buffer was added. The concentration of protein was detected by BCA kit (Thermo Fisher Scientific, Waltham, MA, USA). SDS-Polyacrylamide gel electrophoresis was carried out for $30 \mu \mathrm{g}$ of the total proteins. After electrophoresis, the proteins were removed to a PVDF membrane (Amersham, USA). 5\% skim milk powder was added to block the membrane at room temperature for $1 \mathrm{~h}$. After discarding the blocking solution, CD63 (ab59479, 1:10,000, abcam, Cambridge, UK), CD9 (ab92726, 1:2000, abcam, Cambridge, UK), TSG101 (ab125011, 1:2000, abcam, Cambridge, UK), CD19 (ab134114, 1:2000, abcam, Cambridge, UK), CD40 (ab224639, 1:1000, abcam, Cambridge, UK) and GAPDH (ab9485, 1:2500, abcam, Cambridge, UK) were added to the membrane for incubation at $4{ }^{\circ} \mathrm{C}$ overnight. All of the primary antibodies were rabbit polyclonal antibodies. Then, PBST (PBS buffer containing 0.1\% Tween-20) was subject to the membrane 3 times, $10 \mathrm{~min}$ at a time. After that, horseradish peroxidase-labeled secondary Goat anti-rabbit IgG H\&L (ab6721, 1:2000, abcam, Cambridge, UK) was added and incubated at room temperature for 
$1 \mathrm{~h}$. PBST was again applied to wash the membrane 3 times, $10 \mathrm{~min}$ at a time. After the protein being scanned and developed, the protein signals were photographed with the optical luminometer (GE, USA).

\section{MTT assay}

MTT assay was applied to measure the proliferation of ALL cells. The treated cell line $\left(5 \times 10^{3}\right.$ cells $\left./ 100 \mu \mathrm{l}\right)$ was plated into a 96-well plate. After 24, 48 and $72 \mathrm{~h}$, the cell proliferation was evaluated with sterile MTT solution (Beyotime). Spectrophotometer (Molecular Devices, Sunnyvale, CA, USA) was utilized to observe and record the optical density at $570 \mathrm{~nm}$.

\section{Cell cycle analysis}

The seeded concentration of cells in a 6-well plate was $5 \times 10^{4}$ cells $/ \mathrm{ml}$, with about $2 \mathrm{ml}$ of cell suspension. After $72 \mathrm{~h}$, the cell suspension was centrifuged at $1000 \times g$ for 3 min for cell collection. Thereafter, the cells were kept overnight with $70 \%$ ethanol at $4{ }^{\circ} \mathrm{C}$ for fixation. The next day, after the centrifugation for cells, the supernatant was decanted. The cells acquired were subject to PBS for wash. Afterwards, the cells were dyed with $20 \mu \mathrm{g} / \mathrm{ml}$ propidium iodide (PI) solution (Sigma, USA) and $200 \mu \mathrm{g} /$ $\mathrm{ml}$ RNase A (Sangon, China) at $37{ }^{\circ} \mathrm{C}$ for $30 \mathrm{~min}$ in the dark, and then cells underwent flow cytometry (BD Biosciences, USA). Pulse signals acquired from flow cytometry were evaluated by ModFit software (Verity Software House, Topsham, ME).

\section{Cell apoptosis assay}

Cell apoptosis was measured by the Annexin V-PI fluorescein staining kits (Bender Medsystems, Austria). $5 \times 10^{4}$ cells were suspended in $500 \mu \mathrm{l}(1 \times)$ binding buffer (10 mM HEPES, $\mathrm{pH}=7.4,140 \mathrm{mM} \mathrm{NaCl}, 2.5 \mathrm{mM} \mathrm{CaCl}_{2}$ ). Then, the cells were blocked with Annexin V (1:20) for $5 \mathrm{~min}$ and PI was subsequently added for $15 \mathrm{~min}$. Thereafter, cells were subject to flow cytometry.

\section{Extraction of EVs}

The serum collected underwent centrifugation at $12,000 \times g$ at $10{ }^{\circ} \mathrm{C}$ for $20 \mathrm{~min}$. Then it was moved into a $4 \mathrm{ml}$ ultracentrifugation tube. Fixed angle rotor $\mathrm{Ti}$ 50.4 (Beckman Coulter) was used and the serum samples underwent centrifugation at $10,000 \times g$ at $10{ }^{\circ} \mathrm{C}$ for $70 \mathrm{~min}$. Subsequently, the supernatant was decanted. EVs were resuspended by $2 \mathrm{ml}$ PBS and then ultracentrifuged at $100,000 \times g$ at $10{ }^{\circ} \mathrm{C}$ for $70 \mathrm{~min}$. The final EVs particles were suspended in $250 \mu \mathrm{l}$ PBS.

\section{Evaluating EVs internalization}

In order to evaluate the internalization of EVs, EVs obtained were revitalized in the buffer in kits from Sigma
Aldrich (Germany), and PKH67 was also added for incubation at room temperature for $5 \mathrm{~min}$. Afterwards, the samples were mixed with PBS with 5\% FBS. The rest dye was removed by ultra-centrifugation at $100,000 \times g$ for $1 \mathrm{~h}$. The stained EVs were co-cultivated with BALL-1 cells (stained by DAPI) for $6 \mathrm{~h}$, and then subject to $4 \%$ paraformaldehyde at $25^{\circ} \mathrm{C}$ for $20 \mathrm{~min}$. The internalization of EVs was evaluated by a fluorescence microscope.

To furtherly examine the internalization, the co-cultured cells were analyzed using flow cytometry. The uptake rate was calculated following the method in the previous study (30087865).

\section{Transwell assay}

Transwell assay was introduced to assess cell migration and invasion abilities using transwell chamber (Corning, USA). For migration assay, the transfected cells were seeded into the upper chamber $\left(10^{5}\right.$ cells/well $)$ in the medium without suppling FBS. Meanwhile, the medium containing $10 \%$ FBS was added to the lower chamber. $24 \mathrm{~h}$ later, the cells on the upper chamber were removed using cotton swab, followed by quantifying migrated cells by MTT assay. For the invasion assay, the upper chamber was coated with Matrigel (BD, USA), and the remaining steps followed the steps in the migration assay.

\section{Statistical analysis}

GraphPad Prism 7 software (GraphPad software, Inc., La Jolla, CA) was adopted to process data. The measurement data were manifested in the form of mean \pm standard deviation. The comparison between groups was conducted by $t$ test, while that among groups was subject to one-way ANOVA. $P<0.05$ indicated a statistical significance.

\section{Results}

\section{High expression of miRNA-181b in ALL}

ALL-related miRNA expression chip GSE56489 (Fig. 1A) was acquired from GEO database, with 14 normal samples and 43 ALL samples. R package "limma" was utilized to acquire DEmiRNAs. $|\operatorname{logFC}|>1.5$ along with adj. pvalue $<0.05$ were the screening standards for DEmiRNAs. In total, 4 DEmiRNAs were obtained, among which miRNA-181b, miRNA-155 and miRNA-146a were upregulated and miRNA-145 was down-regulated (Fig. 1B). miRNA-181b expressed the most significantly. Therefore, miRNA-181b was chosen as the research object.

\section{miRNA-181b-5p regulates the proliferation, apoptosis and cycle of ALL cells}

To furtherly understand the impacts of miRNA-181b-5p on the biological functions of ALL cells, miRNA-181b-5p mimic, mimic NC, miRNA-181b-5p inhibitor, and 


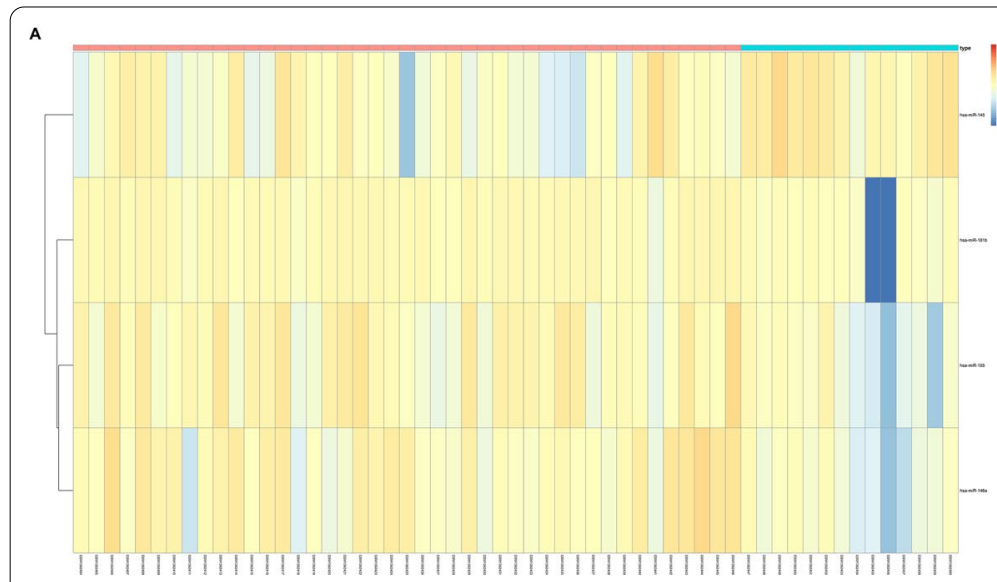

B
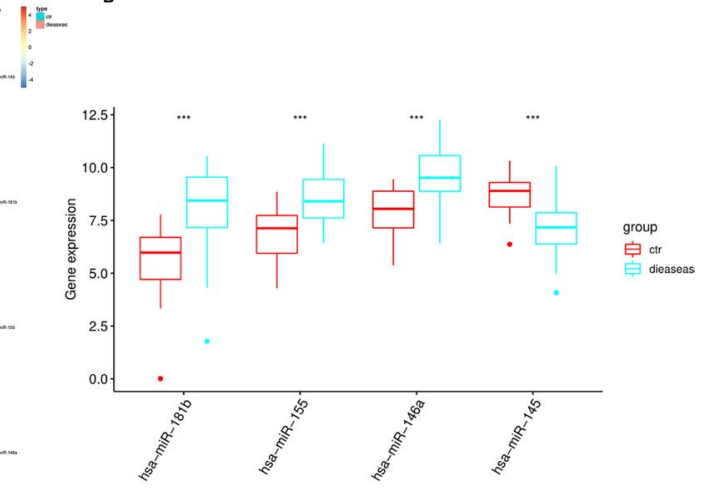

Fig. 1 Highly-expressed miRNA-181b in ALL. A Heatmap of GSE56489 DEmiRNAs; B box plots show differential expression of 4 candidate miRNAs; ${ }^{* * *} p<0.001$

inhibitor NC were transfected with BALL-1 cells. The expression levels of miRNA-181b-5p in the transfected cells were examined to determine transfection efficiency (Fig. 2A). Then, the cell proliferation, apoptosis, cell cycle, migration, and invasion abilities were assessed, and the results revealed the significant effect of miRNA-181b-5p on the biological functions of ALL cells. As shown in Fig. 2B-F, in the miRNA-181b-5p mimic group, cells had higher proliferative ability than the cells in the NC group, with the proportion of cells in G0/G1 phase lowered, while the apoptotic rate decreased. Meanwhile, migration and invasion abilities of cells were strengthened. While the opposite effects were observed in the groups treated with miRNA-181b-5p inhibitor or inhibitor NC. The results indicated that the progression of ALL cells could be promoted after miRNA-181b-5p was overexpressed.

\section{EVs are abundant in peripheral blood of ALL patients and can be internalized by BALL- 1 cells}

The distribution of miRNA-181b-5p was examined via EVmiRNA database, finding that miRNA-181b-5p is mainly presented in exosomes, MVs and exosomes of lymphocytes (Fig. 3A). Therefore, it was speculated whether EVs-derived miRNA-181-5p could enter ALL cells and thus plays a role. Therefore, EVs in peripheral blood samples from ALL patients and healthy people were obtained by ultracentrifugation. Surface marker proteins of EVs were detected via Western blot assay. As the results illustrated, the expression levels of proteins like CD63, CD9, TSG101, CD19 and CD40 were relatively intensive in EVs from ALL patients compared to the healthy group (Fig. 3B). This indicated that EVs from the peripheral blood samples of ALL patients and healthy people were successfully isolated. In addition, qRT-PCR assay unveiled that the expression of miRNA-181b-5p was significantly higher in EVs from patients than that in healthy controls (Fig. 3C). To verify whether miRNA-181b-5p in EVs can enter and affect the activity of ALL cells, EVs from patients were labeled with PKH67 fluorescence and it was found that they were effectively internalized by BALL-1 cells (Fig. 3D).Meanwhile flow cytometry results presented the uptake rate of EVs (Fig. 3E), indicating that EVs can be transferred from serum to the receptor cell BALL-1, and EVs-derived miRNA181b-5p might enter ALL cells through internalization and thus affect the progression of ALL.

\section{miRNA-181b-5p in ALL-derived EVs impacts the proliferation, apoptosis and cell cycle of ALL cells} To further explore the impact of EVs from peripheral blood of ALL patients on ALL cellular functions, BALL-1 cells were co-cultured with EVs derived from ALL and healthy people. The expression of miRNA181b-5p in BALL-1 was remarkably up-regulated in the EVs-ALL group (Fig. 4A), which indicated that miRNA181b-5p from ALL patients could enter BALL-1 cells with its expression improved. Then, MTT was employed to verify the viability of ALL cells in different groups. The results illustrated that the viability of ALL cells in EVs-ALL group was remarkably higher than that in the PBS group (Fig. 4B). The flow cytometry analysis results unveiled that the amount of cells in G0/G1 phase in the EVs-ALL group was significantly decreased (Fig. 4C), and the cell apoptotic rate was significantly lower (Fig. 4D) as well. As the transwell assay indicated, migration and invasion abilities were enhanced by EVsALL treatment (Fig. 4E, F). Our results showed that EVs from ALL patients' blood could enter BALL-1 cells, and miRNA-181b-5p carried by the EVs could accelerate the tumorigenesis functions. 

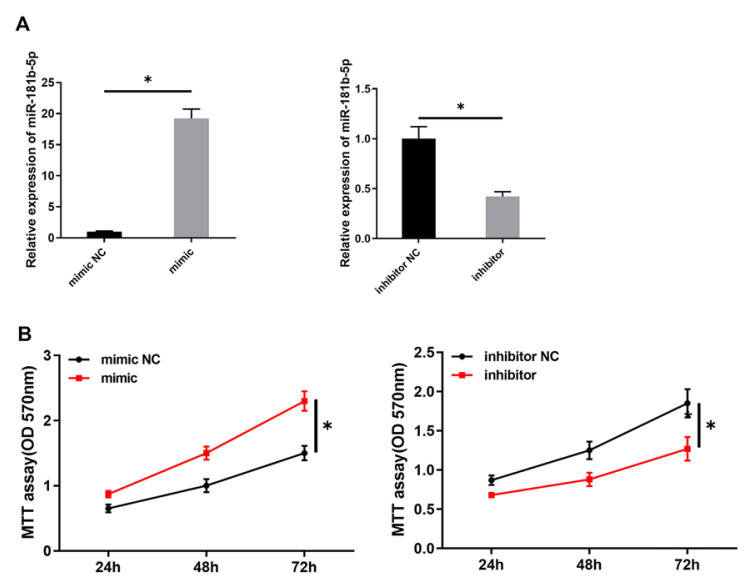

c
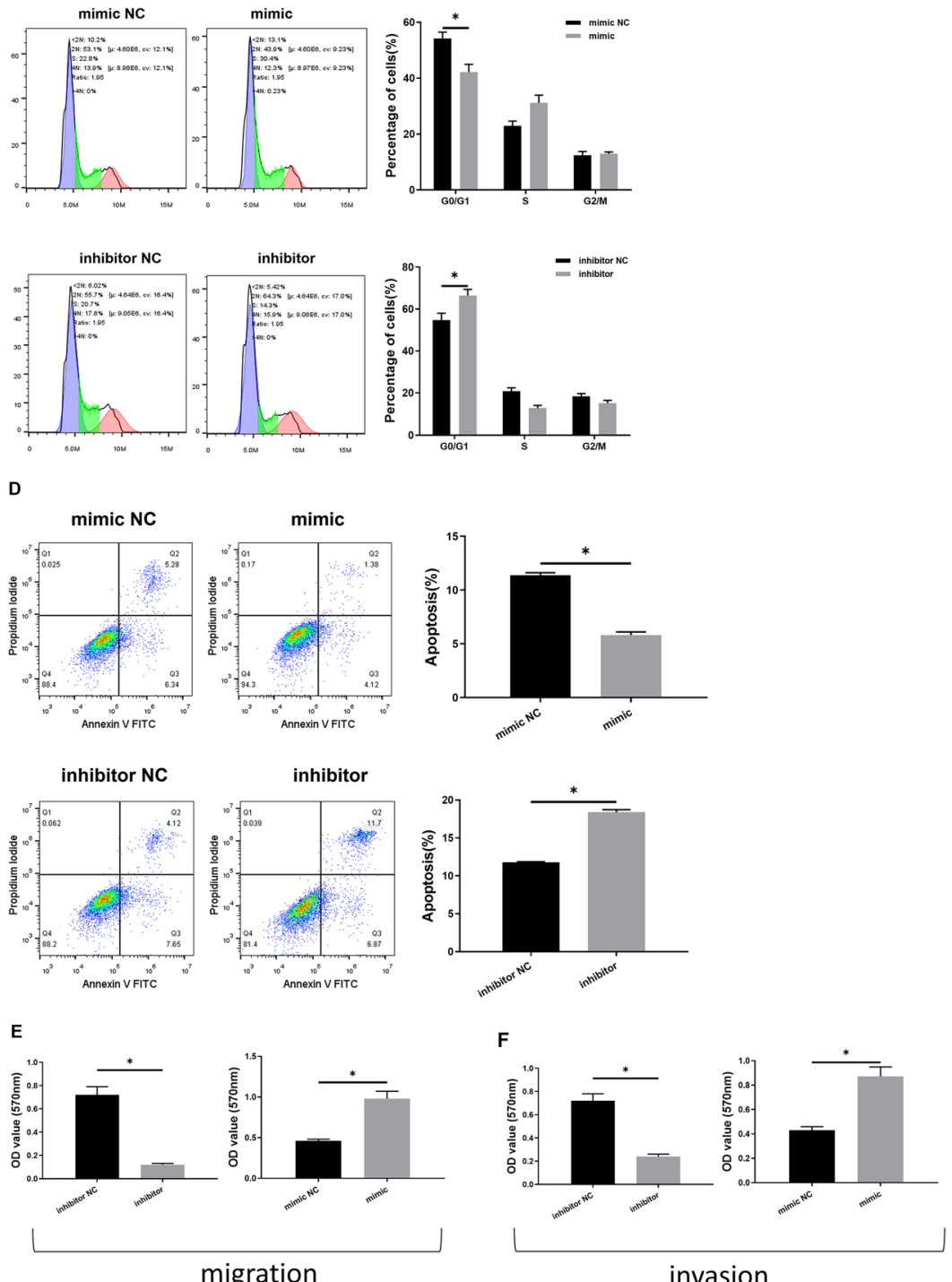

Fig. 2 miRNA-181b-5p regulates the proliferation, apoptosis and cell cycle of ALL cells. A The transfection efficiency; $\mathbf{B}$ the proliferative activities of the cells; $\mathbf{C}$ the cell cycles of the cells; $\mathbf{D}$ the apoptotic rates of the cells; $\mathbf{E}, \mathbf{F}$ migration and invasion of the cells; ${ }^{*} p<0.05$ 


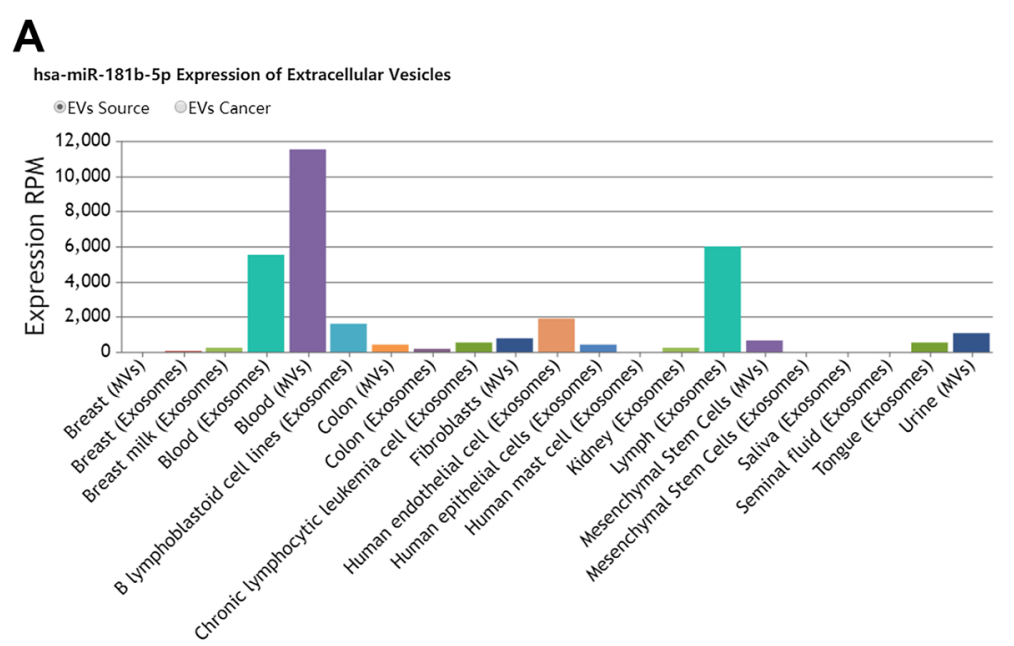

B

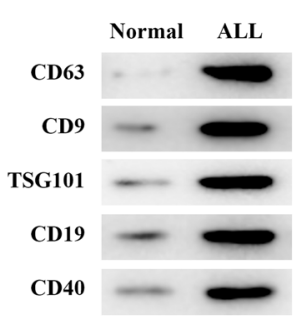

C

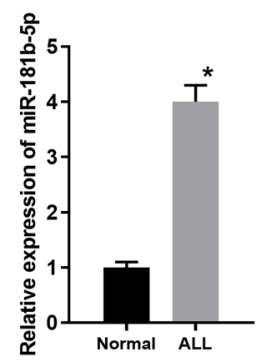

D

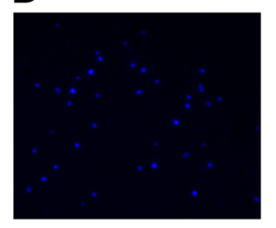

BALL-1

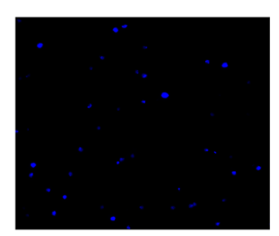

BALL-1

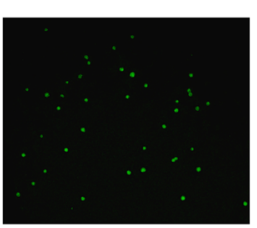

EVs/BALL-1（1\#）

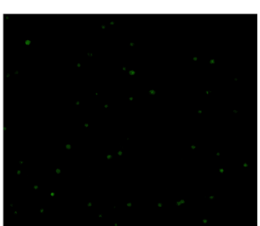

EVs/BALL-1 (2\#)

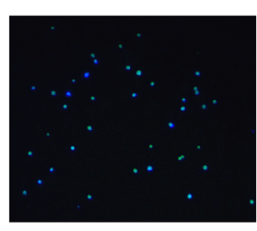

Merged

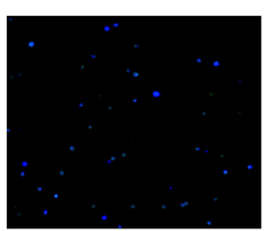

Merged

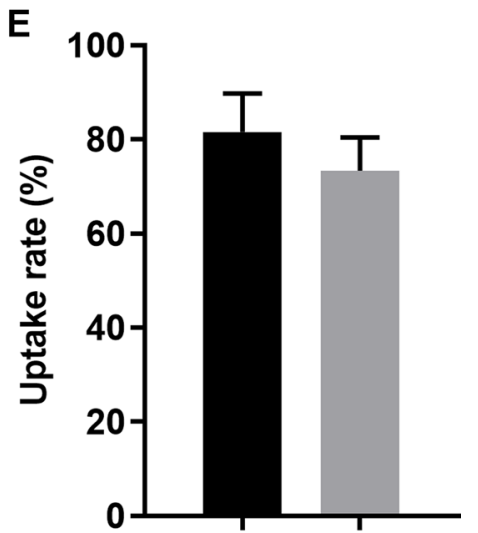

Normal ALL

Fig. 3 EVs are abundant in peripheral blood of ALL patients and can be internalized by BALL-1 cells. A Expression column diagram of miRNA-181 b-5p in EVs from different tissues, with the X-axis representing cell type and the Y-axis representing expression RPM; $\mathbf{B}$ protein expression of surface markers of EVs from healthy people and ALL patients; $\mathbf{C}$ the expression level of miRNA-181b-5p in EVs from healthy people and ALL patients; $\mathbf{D}$ the internalization of EVs by BALL-1 cells; $\mathbf{E}$ the EVs uptake rate was calculated by flow cytometry; ${ }^{*} p<0.05$

\section{Discussion}

Overexpression and tumorigenesis roles of miRNA181b-5 have been identified in gallbladder cancer and non-small cell lung cancer research $[17,18]$, thus we assumed that miRNA-181b-5p may serve as a tumorpromoting factor in ALL patients. Herein, we focused on ALL and studied the expression of miRNA-181b-5p and mechanism of it in peripheral blood-derived EVs of ALL patients.
Firstly, the high expression of miRNA-181b-5p was found in ALL patients through bioinformatics analysis. It was reported that miRNA-181a is significantly up-regulated in ALL and is associated with high probability of MRD and poor prognosis, and it can be used as a prognostic biomarker for child ALL [19]. The study conducted by Rita and others showed that silence of miRNA-181a-1/b-1 represses the progression of oncogene Notch1-induced T-ALL [20]. The up-regulated 


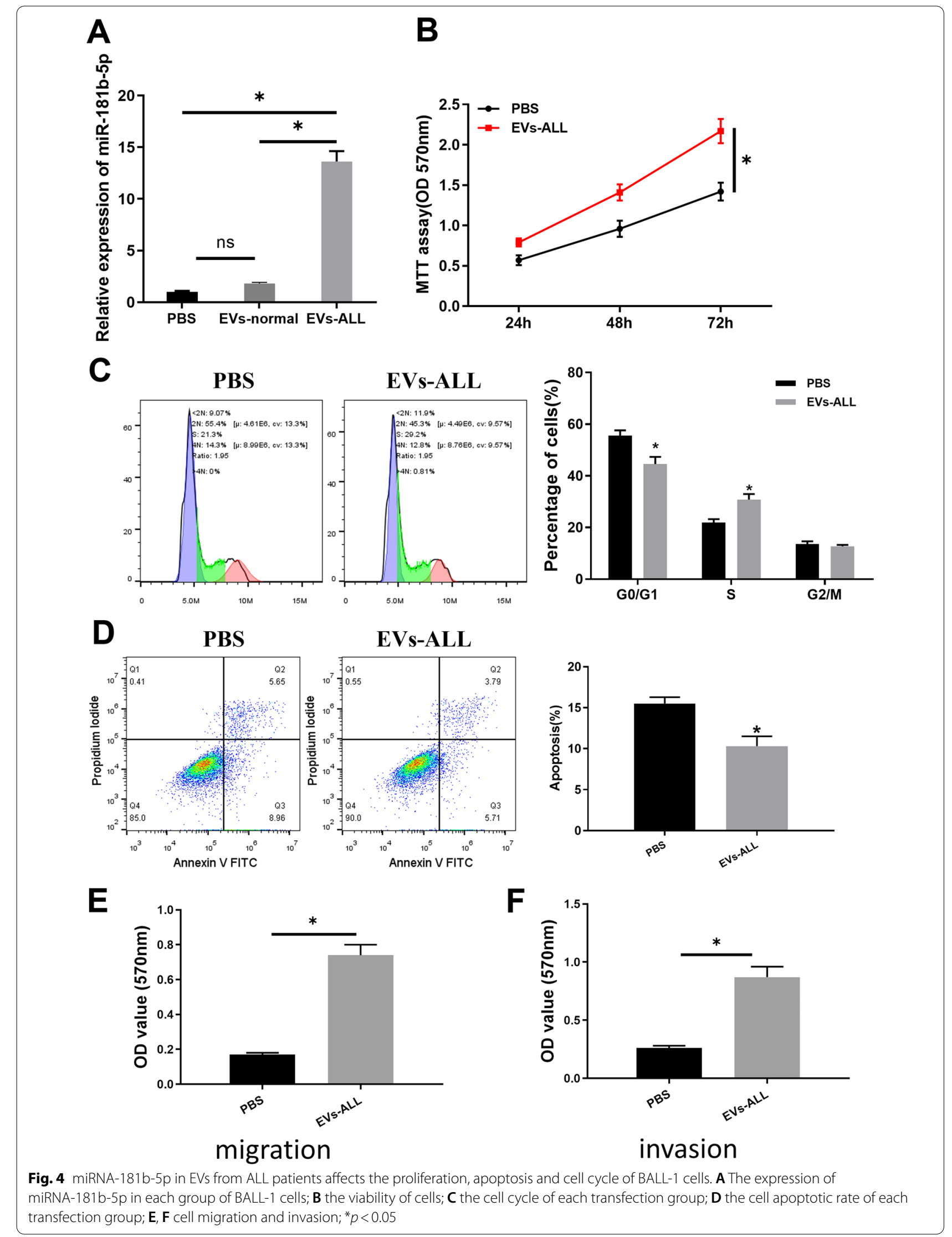

B 
miRNA-181a-5p affects the WIF1 of ALL cells, indicating that miRNA-181a-5p-mediated Wnt signal may be part of the pathogenesis of ALL [21]. In addition, miRNA181b-5p has been reported to promote tumor malignant progression by various pathways $[17,22,23]$, while not been confirmed in ALL yet. These indicated that miRNA181 might be incorporated in the malignant progression of ALL. To verify the function of miRNA-181b-5p in ALL cells, it was overexpressed in ALL cells. The results of cell assays unveiled that overexpressed miRNA-181b-5p remarkably enhanced the proliferation of ALL cells, decreased the amount of cells in G0/G1 phase and the apoptosis of ALL cells.

Additionally, miRNA-181b-5p is proved mainly present in serum exosomes and MVs. Therefore, here, EVs from peripheral blood of ALL patients and healthy people were extracted. Western blot was employed to test expression of EVs markers including CD63, CD9, TSG101, CD19 and CD40 and it was identified that EVs were successfully isolated. Further qRT-PCR results revealed that the expression of miRNA-181b-5p was significantly higher in EVs of ALL patients than that of healthy people. It is reported that miRNA-26a carried by exosomes derived from glioma stem cells can promote angiogenesis of glioma microvascular endothelial cells [24]. Mature T-cell leukemia/lymphoma cells can release EVs containing miRNA-21, miRNA-155 and vascular endothelial growth factor (VEGF), inducing NF- $\mathrm{kB}$ activation, resulting in changing of cellular morphology and increasing of proliferation, migration and angiogenic markers in recipient mesenchymal stem cells [25]. In this study, the extracted EVs were labeled with PKH67, and it was found that miRNA-181b-5p can be delivered into ALL cells by EVs. However, in this section, we did not entirely confirm the internalization process, which means the EVs may be attached to the surface of ALL cell membrane but not be absorbed into the cell. For this limitation, we are planning to arrange some more appropriate experiments to strengthen the logic of the study. Then, in order to prove that miRNA-181b-5p could enter ALL cells and affect the cell proliferation, cycle and apoptosis, MTT and flow cytometry were conducted for the EVs-ALL group. The results unveiled that cell proliferation was remarkably improved. These results suggest that EVs from peripheral blood of ALL patients can enter ALL cells and affect their proliferative capability. Interestingly, one research posted by Ying Wang identified a pro-angiogenetic role of EVsderived miRNA-181b-5p in esophageal squamous carcinoma [23]. However, this effect was not examined in our study, so which we are planning an in-depth study on it in our next step.

In conclusion, our data demonstrate that miRNA181b-5p carried by EVs from patients with ALL was capable of promoting the progression of ALL cells, affecting cell cycle and inhibiting the apoptosis of cancer cells. This may lay a good foundation for our future research regarding the influence of EVs on ALL.

\section{Acknowledgements \\ Not applicable.}

\section{Authors' contributions}

WYan contributed to the study design. LS conducted the literature search. HW acquired the data. WYan wrote the article. LS and HW performed data analysis. WYang and $\mathrm{LH}$ revised the article. YYang gave the final approval of the version to be submitted. All authors read and approved the final manuscript.

\section{Funding}

None.

Availability of data and materials

All the original data of this study are available from the corresponding author upon request.

\section{Declarations}

Ethics approval and consent to participate

This study was conducted in accordance with the Helsinki Declaration II and was approved by Shengjing Hospital of China Medical University (KYCS2021239).

\section{Consent for publication}

Not applicable.

Competing interests

No competing interests at all.

\section{Author details}

'Department of Hematology, Shengjing Hospital of China Medical University, Shenyang 110000, People's Republic of China. ${ }^{2}$ National Drug Clinical Trial Institute Office, Qingdao Women and Children's Hospital, Qingdao, China.

${ }^{3}$ Shanghai Engineering Research Center of Pharmaceutical Translation, Shanghai, China.

Received: 1 June 2021 Accepted: 30 November 2021

Published online: 18 December 2021

References

1. Moorman AV, et al. Karyotype is an independent prognostic factor in adult acute lymphoblastic leukemia (ALL): analysis of cytogenetic data from patients treated on the Medical Research Council (MRC) UKALLXII/Eastern Cooperative Oncology Group (ECOG) 2993 trial. Blood. 2007;109:3189-97. https://doi.org/10.1182/blood-2006-10-051912.

2. Goldstone $\mathrm{AH}$, et al. In adults with standard-risk acute lymphoblastic leukemia, the greatest benefit is achieved from a matched sibling allogeneic transplantation in first complete remission, and an autologous transplantation is less effective than conventional consolidation/maintenance chemotherapy in all patients: final results of the International ALL Trial (MRC UKALL XII/ECOG E2993). Blood. 2008;111:1827-33. https://doi. org/10.1182/blood-2007-10-116582.

3. Ward E, DeSantis C, Robbins A, Kohler B, Jemal A. Childhood and adolescent cancer statistics, 2014. CA Cancer J Clin. 2014;64:83-103. https://doi. org/10.3322/caac.21219.

4. Hunger SP, et al. Improved survival for children and adolescents with acute lymphoblastic leukemia between 1990 and 2005: a report from the children's oncology group. J Clin Oncol. 2012;30:1663-9. https://doi.org/ 10.1200/JCO.2011.37.8018.

5. Geyer MB, et al. Overall survival among older US adults with ALL remains low despite modest improvement since 1980: SEER analysis. Blood. 2017;129:1878-81. https://doi.org/10.1182/blood-2016-11-749507. 
6. Aldoss I, Stein AS. Advances in adult acute lymphoblastic leukemia therapy. Leuk Lymphoma. 2018;59:1033-50. https://doi.org/10.1080/ 10428194.2017.1354372.

7. Keller S, Ridinger J, Rupp AK, Janssen JW, Altevogt P. Body fluid derived exosomes as a novel template for clinical diagnostics. J Transl Med. 2011;9:86. https://doi.org/10.1186/1479-5876-9-86.

8. Becker A, et al. Extracellular vesicles in cancer: cell-to-cell mediators of metastasis. Cancer Cell. 2016;30:836-48. https://doi.org/10.1016/j.ccell. 2016.10.009.

9. Gould SJ, Raposo G. As we wait: coping with an imperfect nomenclature for extracellular vesicles. J Extracell Vesicles. 2013. https://doi.org/10.3402/ jev.v2i0.20389.

10. Raposo G, Stoorvogel W. Extracellular vesicles: exosomes, microvesicles, and friends. J Cell Biol. 2013;200:373-83. https://doi.org/10.1083/jcb. 201211138.

11. Kuhse J, et al. Alternative splicing generates two isoforms of the alpha 2 subunit of the inhibitory glycine receptor. FEBS Lett. 1991;283:73-7. https://doi.org/10.1016/0014-5793(91)80557-j.

12. Valadi $\mathrm{H}$, et al. Exosome-mediated transfer of mRNAs and microRNAs is a novel mechanism of genetic exchange between cells. Nat Cell Biol. 2007;9:654-9. https://doi.org/10.1038/ncb1596.

13. Thery C, Ostrowski M, Segura E. Membrane vesicles as conveyors of immune responses. Nat Rev Immunol. 2009;9:581-93. https://doi.org/10. 1038/nri2567.

14. Ciardiello $\mathrm{C}$, et al. Focus on extracellular vesicles: new frontiers of cell-tocell communication in cancer. Int J Mol Sci. 2016;17:175. https://doi.org/ 10.3390/ijms17020175.

15. Kosaka N, et al. Trash or treasure: extracellular microRNAs and cell-to-cell communication. Front Genet. 2013;4:173. https://doi.org/10.3389/fgene. 2013.00173.

16. LiWY, et al. Detection of microvesicle miRNA expression in ALL subtypes and analysis of their functional roles. J Huazhong Univ Sci Technolog Med Sci. 2014;34:640-5. https://doi.org/10.1007/s11596-014-1330-0.

17. Qin Y, et al. Downregulation of miR-181b-5p inhibits the viability, migration, and glycolysis of gallbladder cancer by upregulating PDHX under hypoxia. Front Oncol. 2021;11: 683725. https://doi.org/10.3389/fonc.2021. 683725.

18. Li X, Han J, Zhu H, Peng L, Chen Z. miR-181 b-5p mediates TGF- $\beta 1$ induced epithelial-to-mesenchymal transition in non-small cell lung cancer stem-like cells derived from lung adenocarcinoma A549 cells. Int J Oncol. 2017;51:158-68. https://doi.org/10.3892/ijo.2017.4007.

19. El-Khazragy N, Noshi MA, Abdel-Malak C, Zahran RF, Swellam M. miRNA155 and miRNA-181a as prognostic biomarkers for pediatric acute lymphoblastic leukemia. J Cell Biochem. 2019;120:6315-21. https://doi. org/10.1002/jcb.27918.

20. Fragoso R, et al. Modulating the strength and threshold of NOTCH oncogenic signals by mir-181a-1/b-1. PLoS Genet. 2012;8: e1002855. https:// doi.org/10.1371/journal.pgen.1002855.

21. Lyu X, et al. miR-181a-5p, an inducer of Wnt-signaling, facilitates cell proliferation in acute lymphoblastic leukemia. Oncol Rep. 2017;37:1469-76. https://doi.org/10.3892/or.2017.5425.

22. Li X, Han J, Zhu H, Peng L, Chen Z. miR181b5p mediates TGFbeta1induced epithelial-to-mesenchymal transition in non-small cell lung cancer stem-like cells derived from lung adenocarcinoma A549 cells. Int J Oncol. 2017;51:158-68. https://doi.org/10.3892/ijo.2017.4007.

23. Wang $Y$, et al. Tumor-derived EV-encapsulated miR-181 b-5p induces angiogenesis to foster tumorigenesis and metastasis of ESCC. Mol Ther Nucleic Acids. 2020;20:421-37. https://doi.org/10.1016/j.omtn.2020.03. 002.

24. Wang ZF, Liao F, Wu H, Dai J. Glioma stem cells-derived exosomal miR-26a promotes angiogenesis of microvessel endothelial cells in glioma. J Exp Clin Cancer Res. 2019;38:201. https://doi.org/10.1186/s13046-019-1181-4.

25. El-Saghir J, Nassar F, Tawil N, El-Sabban M. ATL-derived exosomes modulate mesenchymal stem cells: potential role in leukemia progression. Retrovirology. 2016;13:73. https://doi.org/10.1186/s12977-016-0307-4.

\section{Publisher's Note}

Springer Nature remains neutral with regard to jurisdictional claims in published maps and institutional affiliations.

Ready to submit your research? Choose BMC and benefit from:

- fast, convenient online submission

- thorough peer review by experienced researchers in your field

- rapid publication on acceptance

- support for research data, including large and complex data types

- gold Open Access which fosters wider collaboration and increased citations

- maximum visibility for your research: over $100 \mathrm{M}$ website views per year

At BMC, research is always in progress.

Learn more biomedcentral.com/submissions 